\title{
Optimal Stopping and Losses on Subprime Mortgages
}

\author{
DENNIS R. CAPOZZA \\ University of Michigan Business School, Ann Arbor, MI 48109-1234, USA \\ E-mail: capozza@umich.edu
}

THOMAS A. THOMSON

University of Texas, San Antonio, TX 78249-0633, USA

E-mail: tthomson@utsa.edu

\begin{abstract}
Lender losses on mortgage loans arise from a two-stage process. In the first stage, the borrower stops making payments if and when default is optimal. The second stage is a lengthy and costly period during which the lender employs legal remedies to obtain possession and execute a sale of the collateral. This research uses data on subprime mortgage losses to explore the role of borrower and collateral characteristics, and local legal requirements, as well as traditional option variables in the decisions of borrowers and lenders. Although subprime borrowers default earlier, which should reduce lender losses, these borrowers, nevertheless, impose greater realized losses on mortgage lenders.
\end{abstract}

Key Words: $\quad$ subprime, mortgages, defaults, losses, lending

\section{Introduction}

In option pricing models of borrower behavior, the decision to default is an optimal stopping problem. At the optimal time of default, the borrower is balancing the value of the flow of services from the property (the "imputed" rent) versus the size of the mortgage payment and the value of the collateral against the principle balance of the mortgage. If the loan is a recourse loan so that the borrower can be pursued for any deficiency on sale, then borrower assets, income, and credit rating will also play a role in the decision to default.

Clearly, the decision to default is complex and one where the richness of the decision will not be captured in simple option pricing models. Nevertheless, numerous insights arise from viewing the decision from the option pricing perspective.

At what price has the value of the house fallen low enough, so that one's optimal action is to default? Option pricing shows that the house price must be lower than the balance on the loan, and depends on interest rates and transactions costs, not just the value of the home relative to the mortgage. ${ }^{1}$ Because interest rates are determined in national markets, their effect should be similar among borrowers. Transactions costs, however, are more heterogeneous. Relevant considerations include state law and various personal factors including the so-called "trigger events." 
At each payment date, the borrower has the option of: i) making the payment; ii) prepaying the loan; or iii) defaulting. Default can be viewed as exchanging the value of the house for the value of the mortgage. Option pricing models provide the conditions under which default is the optimal strategy for the borrower. For a given set of interest rates, borrower income, transactions costs, and trigger events, the collateral value must hit an optimal stopping boundary, usually defined relative to the outstanding principle on the loan. The optimal strategy maximizes the value of the borrower's "put" option.

In all option models, the parameters of the underlying stochastic processes (e.g., the drift and volatility), are important determinants of the optimal strategy. In most mortgage models, stochastic processes for interest rates and collateral prices drive the model. In more comprehensive models, the borrower's income and assets might also be stochastic. ${ }^{2}$

This research uses a large dataset of subprime mortgage loans from a national lender to provide empirical tests and insights on the subprime borrower's behavior in default and on the resulting losses to the lender. The dataset includes extensive characteristics of the borrower, the loan, and the collateral. Since the dataset includes loans in most states, the effect of different legal institutions can be tested.

On average, subprime borrowers have lower incomes and less wealth (equity) than prime borrowers. As a result, we expect these borrowers to be less able to cope with stressful (trigger) events like unemployment and divorce. From an option theory perspective, defaults motivated by trigger events are not "optimal"; therefore subprime loans provide a laboratory for studying the limits of optimal default in option models.

We dichotomize losses, first, into an expected loss based on optimal behavior in an option-pricing context and, second, by realized losses to the lender. To preview the results, we find that subprime borrowers default earlier (at lower expected current loan-tovalue (LTVs)) than prime borrowers. Earlier default should translate into lower realized losses for lenders on the sale of the collateral, ceteris paribus; but it does not. Losses as a percent of amortized balance at the time of default are higher for subprime borrowers.

The paper is organized into a discussion of the option-pricing model and testable hypotheses (comparative statics) arising from the model, a description of the data, a discussion of the empirical results for expected and realized losses, and a concluding section.

\section{The simulation model}

Our point of departure is the option-based model of mortgage loans in Capozza et al., (1998). ${ }^{3}$ Here we sketch the essential features of the model. A more detailed description is available in Capozza et al., (1998). House prices are assumed to follow geometric Brownian motion, and interest rates to follow the commonly used Ornstein-Uhlenbeck mean reverting process. The simulations use discrete monthly time steps so that once each month, just prior to a mortgage payment, the mortgagor decides whether to prepay, default, or make the scheduled mortgage payment. We abstract from issues surrounding delinquency or delay by assuming that default results in immediate loss of the house in exchange for forgiveness of the debt. 


\subsection{House price process}

House prices $(H)$ are assumed to follow the process:

$$
d H=(g-\gamma) H d t+\sigma_{H} H d W
$$

where

$g=$ the required return on housing given its risk,

$\gamma=$ the rental rate or "rent-to-price" ratio for the house (analogous to the dividend rate on common stock),

$\sigma_{H}=$ the volatility of house prices, and

$W=$ standard Brownian motion.

Hedging arguments (e.g., Hull (1993)) yield the risk neutral pricing process given by

$$
d H=(r-\gamma) H d t+\sigma_{H} H d V
$$

where

$r=$ the risk free interest rate and

$V=$ an alternate Brownian motion.

\subsection{Interest rate process}

We assume that interest rates follow a discrete version of the Ornstein-Uhlenbeck mean reverting process:

$$
d r=\beta(\alpha-r) d t+\sigma_{r} d W
$$

where

$r=$ the interest rate,

$\alpha=$ the equilibrium interest rate to which rates will revert,

$\beta=$ non-negative reversion parameter which describes the intensity at which rates will return to the equilibrium rate, and

$\sigma_{r}=$ the volatility of interest rates.

In Equation (3), if $\beta=0$, the process is a pure random walk model (normal diffusion). When $\alpha=r$, the process is a pure random walk over the next instant. For other parameter values, the interest rate reverts to $\alpha$. The term structure of interest rates is implied by the difference between $r$ and $\alpha$.

\subsection{Transactions costs and trigger events}

Two "real world" considerations are typically incorporated into contingent-claims mortgage termination models. The first consideration is the transactions costs of default; 
and the second consideration is "trigger events" or exogenous events such as job relocation that leads to termination. Transactions costs are incorporated into the default decision by adding a cost term to the outstanding balance at the time of default. Transactions costs include monetary moving costs, social and family costs of the move, and financial disruption from a blemished credit standing or deficiency judgments that claim other assets. In the simulations that follow, transactions costs are modeled as a fixed dollar cost.

A trigger event converts the multi-period default decision into a one period decision. There are two types of trigger events. The first type arises if the borrower must move. In this case, the opportunity or transactions costs of default are minimal since the borrower incurs the costs whether he defaults or not. The second type occurs when the borrower is unable to continue making payments. In this case, the transactions costs remain relevant since default will necessitate a move that need not occur otherwise.

\section{The simulations}

We initiate the analysis by requiring that the mortgage be fairly priced. The coupon rate on a loan at origination must set the present value of payments (including default and prepayment options, and the effect of exogenous terminations) equal to the principle amount. The model parameters are then varied individually from their base case values to determine the effect of changing a parameter's value while holding all other parameters constant. The results are presented graphically to facilitate assessments of the direction, the strength, and the linearity of the relationships.

The model evaluates the optimal stopping boundary expressed as the ratio of mortgage balance to current property value for seasoned mortgages. The range of parameter values was chosen to be realistic (e.g., 360 month mortgages), and to encompass those used in other studies. Table 1 presents the base case and range of parameters. Relevant parameters include the levels and volatilities of house prices and interest rates, the rental rate, the interest rate reversion parameter, transactions costs, and trigger events.

The method of solution is described in Capozza et al. (1998). We present results for the stochastic house price volatility, the interest rate process, transactions costs, remaining term, the exogenous termination rate, and interest rate volatility.

\subsection{House price volatility}

Figure 1 summarizes the effects for six variables. The first panel of the figure illustrates the effect of house price volatility on the current LTV (current loan balance/current house value) stopping boundary. Current LTV at the time of default should be an important determinant of loss severity. As in most contingent claims models, increases in volatility increase the value of an option, viz., the embedded put in the mortgage. The impact on the default decision is to delay default (i.e., exercise of the option) and increase the current LTV (CLTV) or severity at the time of default. 
Table 1. Base case parameters for numerical modeling.

\begin{tabular}{lll}
\hline Variable & Base Case & Range \\
\hline Initial house price, $H_{0}(\$)$ & 100,000 & \\
Initial loan amount, $M B_{0}(\$)$ & 90,000 & \\
Contract mortgage rate $(\%)$ & 0.85 monthly $(10.2$ annual rate $)$ & \\
Monthly mortgage payment, Pmt $(\$)$ & 803.15 & 3 to 16 \\
Initial spot interest rate, $r_{0}(\%)$ & 0.80 monthly $(10.0$ effective annual rate) & \\
Gross return to housing, $g$ & 0.11 & \\
House rental rate, $\gamma$ & 0.05 & 0.02 to 0.18 \\
House price volatility, $\sigma_{H}$ & 0.1 & \\
Reversion parameter, $\beta$ & 0.1 & 0.004 to 0.016 \\
Interest rate equilibrium, $\alpha=r_{0}$ & 0.10 & \\
Interest rate volatility, $\sigma_{r}$ & 0.01 & $-8,000$ to 10,000 \\
Deadweight refinance costs, $(\$)$, & $F=500, X=0.5$ of loan balance \\
$F+X M B(\%)$ & & 0 to 10 \\
Transactions cost of default, $T C(\$)$ & 5,000 & \\
Exogenous prepayment rate, $\lambda_{t}(\%)$ & $0.5(50 \%$ of PSA) & \\
\hline
\end{tabular}

Notes: The parameters and ranges were used in the simulations. The results are invariant to house price. The implied initial loan-to-value is 90 percent. Gross return to housing (11 percent) is similar to discount rates on commercial property (11 percent -12 percent). The rental rates bracket the range of values found by Capozza et al. (1997). House price volatility is also based on values in Capozza et al. (1997). The range of interest rate reversion and volatility parameters are similar to ranges in Chan et al. (1992). Refinance and default costs are similar to Kau et al. (1994). Exogenous prepayment rate is set below (PSA) because optimal defaults are already included in the modeling.

\subsection{Interest rates}

The second panel in Figure 1 illustrates that when spot interest rates increase from the level at origination, the expected severity increases. Higher interest rates reduce the market value of the mortgage, giving the borrower an incentive to delay defaulting, which increases the severity if the loan eventually does default. The effect is larger for rate increases than for decreases. To allow for this asymmetry, we separate increases and decreases in the empirical tests that follow. ${ }^{4}$

\subsection{Transactions costs of default}

Transactions costs are particularly interesting because they can vary in three ways. First, each individual faces different transaction costs from family and job characteristics. It is well known that single individuals are more likely to move than other household types. Second, transactions costs vary by location since the legal remedies available to lenders differ. In one-remedy states, borrowers can default with minimal consequences to their personal finances (see, for example, Jones (1993)). Third, this cost can vary over time for the same individual when personal circumstances change. A divorce or job change can greatly reduce the cost of default since the borrower will need to move independently of 

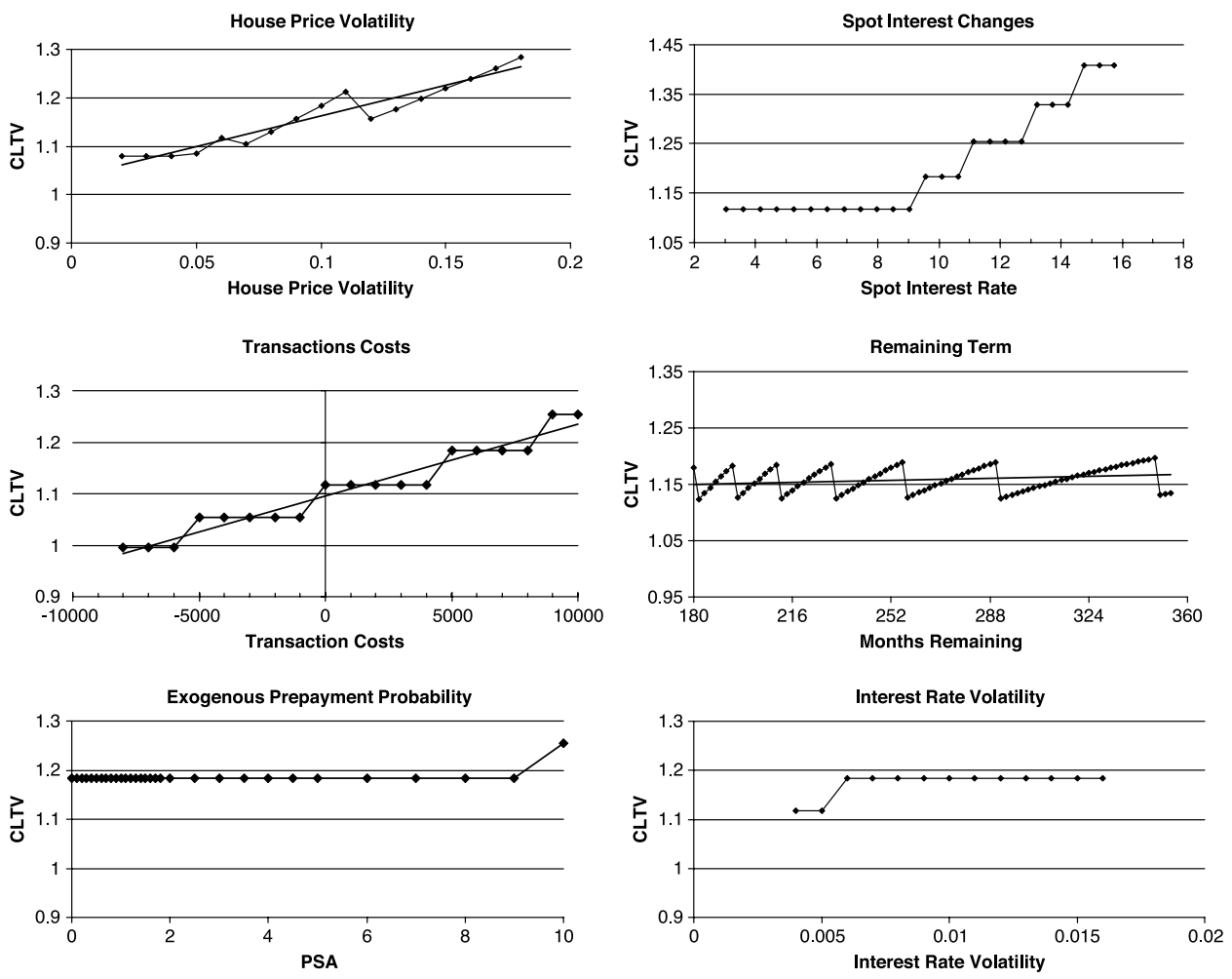

Figure 1. The simulated effect of selected covariates on the optimal stopping boundary.

Notes: The graphs above illustrate the simulated effect of the indicated variable on the stopping boundary for current loan-to-value. The parameters for the base case and the range of variation are described in Table 1. House price volatility, interest rate changes, and transactions costs have the largest effects. More minor effects arise with remaining term, exogenous prepayment probability, and interest rate volatility.

the default decision. Ambrose et al., (1997) point out that transactions costs can even be negative for borrowers who may enjoy a period of free rent before foreclosure is completed.

The third panel in Figure 1 shows the effect of these transactions costs on severity. Higher transactions costs cause borrowers to delay default, thereby increasing severity.

\subsection{Remaining term}

The fourth panel illustrates the effect of remaining term. Remaining term is effectively the time to expiration of the option to default. The effect on severity is quite small when there is substantial time to the end of term (which there is in our data) and is positive as in other contingent claims models. 


\subsection{Exogenous prepayment probability}

The fifth panel shows that the effect of variation in the exogenous probability of prepayment, measured as a multiple of the PSA rate, is quite small. High exogenous prepayments can arise from borrower mobility or other reasons.

\subsection{Interest rate volatility}

The sixth panel shows the effect of interest rate volatility. The effect on severity again is quite small. As with house price volatility, interest rate volatility increases the value of delaying a default and consequently raises severity. Since the variables are difficult to measure and the effects are small, we do not attempt to include proxies for these latter two variables in the empirical analysis.

\subsection{Trigger events}

Historically, industry analysts have assumed that exogenous events (e.g., divorce or unemployment) play a major role in mortgage default. In the model, exogenous events are random events with a given probability of occurrence. The borrower realizes that exogenous events may occur in the future, and adjusts the decision to default or prepay appropriately. We can separate the defaults into those that are due to the optimal decision at the time, and those which are a response to an exogenous event. In the base case, it is assumed that transactions costs are present for all default decisions. In many cases, however, an exogenous event may result in several changes for the decision maker-some of which may reduce the transactions costs of defaulting to zero. For example, if a move results from this exogenous event (perhaps a change of employment location), then the moving costs are no longer relevant to the default decision. For this reason, Capozza et al., (1998) also analyzed a modified model when transactions costs are zero if the exogenous event occurs. If a trigger event occurs, the borrower is more likely to default because a trigger event removes the option value of delay. When transactions costs are assumed to fall to zero if a trigger event occurs, borrowers do default at a higher rate. However, the overall conclusion is that trigger events play a minor role.

\section{The data description}

The data are loans from a national lender of subprime loans with borrowers over a wide range of ages, credit scores, and loan terms. The loans were originated from 1994 to 2001 under a broad range of interest rates and economic conditions. During this period 4,010 loans defaulted. 
The data encompass loans in most states, and on a variety of properties including, mobile homes, condominiums, and units with up to four dwellings, in addition to singlefamily homes. There are indicators for whether the property is owner occupied, or is an investment property. Loan type includes both variable and fixed rate loans. Prepayment penalties were in force for many of the loans during their early life. While we do not have complete coverage of credit scores, we have scores for about 40 percent of the loans, with an average credit score of 556, which is very much subprime. ${ }^{5}$ Additional borrower information that has not been available to other researchers includes time at job, time at property, payment-to-income and debt-to-income, and purpose of the loan (e.g., purchase, cash-out refinance, etc.). Table 2 reports summary statistics for selected variables.

\subsection{Variable descriptions}

Five types of variables are included in the analysis of the stopping boundary and of the losses and expenses. We group these into variables motivated by option pricing, borrower characteristics, variables describing the judicial process, collateral characteristics, and variables that attempt to capture trigger events.

\subsection{Option variables and loan terms}

"Expected CLTV at Default" is the ratio of the amortized balance at default to the appraised value at origination adjusted for the change in market prices as measured by the Office of Federal Housing Enterprise Oversight (OFHEO) price index for the state. This variable attempts to measure the current LTV at the time the borrower makes the decision to default.

"Remaining Term" is the number of months remaining on the loan at the time of default. This is a measure of time to expiration of the put option, and the expected sign in the stopping boundary equation is positive.

"House Price Volatility" is the OFHEO measure of annual house price volatility arising from the estimates of repeat sales indices for each state.

"Interest Rate Changes (Up and Down)" is the change in market interest rates since loan origination.

"Loan Age ${ }^{1 / 2}$ " is the square root of the time since origination. This variable attempts to capture the stochastic evolution of collateral prices. Since defaults are drawn from the tail of the house price distribution and since it takes time for prices to wander from the mean of the distribution, we expect that defaults can occur at lower market prices for older loans.

Other loan characteristics that are available in the dataset include indicators of fixed versus variable rates, discount points, and prepayment penalties. 
Table 2. Summary statistics.

\begin{tabular}{|c|c|c|c|c|}
\hline Variable & Mean & Standard Deviation & Minimum & Maximum \\
\hline \multicolumn{5}{|l|}{ Option variables and loan terms } \\
\hline LTV at Origination & 0.79 & 0.10 & 0.45 & 1.08 \\
\hline Expected CLTV at default & 0.72 & 0.08 & 0.39 & 0.98 \\
\hline Interest rate up & 0.33 & 0.45 & 0.00 & 2.32 \\
\hline Interest rate down & 0.29 & 0.43 & 0.00 & 2.48 \\
\hline Term (months) & 352 & 34 & 120 & 360 \\
\hline Loan age (months) & 14.31 & 10.99 & 2.00 & 83.00 \\
\hline Fixed rate & 0.29 & 0.45 & 0.00 & 1.00 \\
\hline Discount points & 5.41 & 2.12 & 0.00 & 12.00 \\
\hline Prepayment penalty & 0.68 & 0.47 & 0.00 & 1.00 \\
\hline House price index (OFHEO) & 1.05 & 0.05 & 0.86 & 1.42 \\
\hline \multicolumn{5}{|l|}{ Borrower characteristics } \\
\hline Interest rate premium & 3.45 & 1.55 & -2.76 & 9.66 \\
\hline Cash-out refinance & 0.52 & 0.50 & 0.00 & 1.00 \\
\hline Not owner occupied & 0.14 & 0.34 & 0.00 & 1.00 \\
\hline Low documentation & 0.44 & 0.50 & 0.00 & 1.00 \\
\hline Purchase money & 0.32 & 0.47 & 0.00 & 1.00 \\
\hline Credit score $(N=1,597)$ & 556 & 55 & 420 & 787 \\
\hline Loan payment-to-income & 0.22 & 0.10 & 0.01 & 0.81 \\
\hline Total debt obligations-to-income & 0.35 & 0.13 & 0.00 & 0.85 \\
\hline Time on job & 6.35 & 7.46 & 0.00 & 50.00 \\
\hline Time in property & 4.82 & 8.76 & 0.00 & 255 \\
\hline \multicolumn{5}{|l|}{ Judicial process } \\
\hline Slow foreclosure state & 0.36 & 0.48 & 0.00 & 1.00 \\
\hline \multicolumn{5}{|l|}{ Collateral characteristics } \\
\hline Manufactured housing & 0.04 & 0.20 & 0.00 & 1.00 \\
\hline Condo & 0.03 & 0.17 & 0.00 & 1.00 \\
\hline Multi-family & 0.08 & 0.28 & 0.00 & 1.00 \\
\hline \multicolumn{5}{|l|}{ Trigger events } \\
\hline Divorce rate & 4.28 & 0.96 & 1.70 & 6.60 \\
\hline Unemployment rate & 4.51 & 1.26 & 1.90 & 9.30 \\
\hline
\end{tabular}

Notes: This table displays summary statistics for selected variables in the database. "Expected CLTV at Default" is the amortized balance at default divided by the purchase price adjusted for market appreciation. "Interest Rate Premium" is the difference between the coupon on the loan and the prime mortgage rate at the time of origination. "Low Documentation" is an indicator that the loan is not fully documented (e.g., sources of income). "Slow Foreclosure States" are the states that Fannie Mae (FNMA) has identified as having a slow foreclosure process usually because judicial proceedings and long redemption periods are required. There are 4,010 observations in the dataset.

\subsection{Borrower characteristics}

"Interest Rate Premium" is the premium of the mortgage contract rate above the prime mortgage rate at the time of origination. Since these are subprime loans, the interest premium charged by the lender is a measure of the quality of the borrower as assessed by the lender at origination. In the empirical analysis that follows, we use this variable 
rather than the credit bureau score because it is a more comprehensive measure of the lender's assessment of borrower quality than credit bureau scores and because bureau scores are missing for many of the observations.

"Cash-Out Refinance" is an indicator variable that the borrower increased the balance of the mortgage at the time of origination (i.e., refinanced). This is a measure of the discount rate and savings behavior of the borrower.

"Not Owner Occupied" is an indicator that the property is not owner occupied.

"Low Documentation" is an indicator that the borrower provided limited or no documentation of income and assets.

\subsection{Judicial process}

"Slow Foreclosure State" is an indicator that Fannie Mae (FNMA) views the state legal process as slow and expensive, primarily because of judicial sales and long redemption periods.

\subsection{Collateral characteristics}

"Manufactured Housing" is an indicator that the property is a manufactured home.

"Condo" is an indicator that the property is structured as a condominium.

"House Age" is the age of the property in years.

\subsection{Trigger events}

"Unemployment" is the state unemployment rate at the time of default.

"Divorce" is the state divorce rate at the time of default.

\section{The empirical results}

\subsection{Analysis of the stopping boundary: Expected losses and time to default}

This section analyzes the stopping boundary or current LTV that triggers default. Our initial analysis investigates the relationship between the stopping boundary and variables that measure option-theory constructs, borrower characteristics, foreclosure costs, and trigger events. The analysis complements the earlier work of Lekkas et al., (1993), Crawford and Rosemblatt (1995), and Ambrose et al., (2001). Our focus is on subprime mortgages where borrower idiosyncrasies are likely to be more important. Our more detailed dataset allows us to probe more deeply into many issues raised earlier. 
The results appear in Table 3. Model 1 includes only the option pricing variables as regressors. The dependent variable is a measure of current LTV at the time of default where the numerator is the balance on the loan at default and the denominator is the review appraisal done at origination, adjusted for changes in market prices as measured by the OFHEO repeat sales indices. The denominator reflects only the market price movements and not the property-specific movements in prices. In general, we expect properties that actually default to be drawn from the tail of the house price distribution. If house prices follow the typical diffusion process, then a specific property can deviate more from the initial price in proportion to the square root of time. Therefore, we include root time as an independent variable to capture the idiosyncratic movements. In all the models of Table 3 , root time is highly significant and has the expected sign.

The second variable in Model 1 is the remaining term on the mortgage. The coefficient is positive and significant, which is consistent with the expectation from the simulation. With a distant expiration date on the option to default, borrowers will optimally wait and default at higher CLTVs (lower collateral prices).

Table 3. The stopping boundary: analysis of expected losses.

\begin{tabular}{|c|c|c|c|c|c|c|}
\hline & \multicolumn{2}{|l|}{ Model 1} & \multicolumn{2}{|l|}{ Model 2} & \multicolumn{2}{|l|}{ Model 3} \\
\hline & Coefficient & t-Statistic & Coefficient & t-Statistic & Coefficient & t-Statistic \\
\hline \multicolumn{7}{|l|}{ Option theory } \\
\hline Intercept & 0.68 & 36.9 & 0.80 & 46.4 & 0.78 & 43.8 \\
\hline$(\text { Loan age })^{* *^{1 / 2}}$ & -0.017 & -18.0 & -0.020 & -22.8 & -0.020 & -22.7 \\
\hline Remaining term & 0.0037 & 9.6 & 0.0024 & 6.8 & 0.0025 & 7.0 \\
\hline HP volatility & -0.018 & -0.1 & -0.062 & -0.4 & -0.34 & -2.1 \\
\hline Interest rate up & 0.011 & 3.7 & 0.010 & 3.9 & 0.011 & 4.1 \\
\hline Interest rate down & -0.0073 & -2.2 & -0.0086 & -2.9 & -0.010 & -3.5 \\
\hline \multicolumn{7}{|c|}{ Borrower/transactions costs } \\
\hline Interest rate premium & & & -0.013 & -17.7 & -0.012 & -16.9 \\
\hline Cash-out refinance & & & -0.014 & -6.8 & -0.016 & -7.4 \\
\hline Not owner occupied & & & -0.034 & -11.3 & -0.035 & -11.3 \\
\hline Low documentation & & & -0.033 & -15.5 & -0.034 & -16.0 \\
\hline \multicolumn{7}{|l|}{ Foreclosure costs } \\
\hline Slow foreclosure state & & & -0.0059 & -2.7 & -0.00091 & -0.3 \\
\hline \multicolumn{7}{|l|}{ Trigger events } \\
\hline Divorce rate & & & & & 0.0053 & 4.4 \\
\hline Unemployment rate & & & & & 0.0040 & 4.2 \\
\hline \multicolumn{7}{|l|}{$\mathrm{R}^{2} \mathrm{~T}-\mathrm{T}^{2}$} \\
\hline & \multicolumn{2}{|c|}{0.15} & \multicolumn{2}{|c|}{0.30} & \multicolumn{2}{|c|}{0.31} \\
\hline
\end{tabular}

Notes: Dependent variable is the "Expected CLTV at Default" (i.e., the current loan-to-value ratio at the time of default), defined as the ratio of the outstanding balance on the loan at the last payment date to the appraised value of the property at the time of loan origination adjusted for changes in the OFHEO local house price index. 
The OFHEO measure of house price volatility is not statistically significant. This result is consistent with the hypothesis that subprime borrowers either are not aware of differences in volatility or ignore the differences if they are aware.

Changes in interest rates since origination are expected to have a positive impact on the stopping boundary. The results are consistent with this expectation. The simulation suggests that the impact of interest rates is greater for increases than for decreases. There is weak support for this result since the absolute value of the "Interest Rate Up" coefficient is greater than the "Interest Rate Down" coefficient, but the difference is not statistically significant.

Overall, Model 1 provides support for the hypothesis that borrowers time defaults in ways that are consistent with option pricing theory. It is worth noting that the mean of the dependent variable, CLTV, is only 72 percent, even though the loss on the sale of defaulted properties is 23 percent, which implies a CLTV of 130 percent. The current LTV at the time of default (our dependent variable) is adjusted only for changes in market prices since origination. This implies that when house prices decline enough to precipitate a default, most of the change is idiosyncratic rather than market related.

Model 2 of Table 3 explores the role of borrower characteristics and foreclosure costs. The option pricing variables have impacts similar to those in Model 1. Among the borrower characteristics is the "Interest Rate Premium" (relative to prime mortgages) paid by the borrower. This variable is a summary statistic for the lenders assessment of the creditworthiness of the borrower. It is highly significant both statistically and economically. Weaker borrowers default earlier (lower stopping boundary).

Three other borrower characteristics are highly significant: "Cash-Out Refinance"; "Not Owner Occupied"; and "Low Documentation." These indicator variables reduce the stopping boundary from 1.4 to 3.4 percent. We interpret the "Cash-Out Refinance" borrowers as having a higher discount rate (and lower savings rate). When the borrower does not occupy the property, transactions costs may be lower (default does not force the borrower to move). "Low Documentation" borrowers are often self-employed and entrepreneurial. Income for these borrowers is more variable, subjecting the borrower to liquidity constraints more frequently.

The final variable in Model 2 is the "Slow Foreclosure State" indicator. In slow foreclosure states, borrowers can live rent-free for a longer period. Free rent acts like a negative transactions cost and encourages default at a lower stopping boundary. The coefficient is significant but small economically, suggesting that even if subprime borrowers are aware of differences in foreclosure requirements, there is little impact on their stopping strategy.

In Model 3, we add the state divorce and unemployment rates at the time of default as measures of trigger events. In both cases, the coefficients do not have the expected sign. Therefore, there is little evidence to support the expected role of trigger events. The remaining coefficients are similar to those in Model 2 with the exception of "Slow Foreclosure State," which loses its significance in Model 3.

To summarize the results of this section, the analysis indicates that both option-pricing and borrower-characteristic variables significantly affect the stopping boundary for subprime mortgage borrowers. There is little evidence to support the expected role of 
trigger events and only weak evidence that legal requirements affect the stopping boundary. Weaker borrowers (higher Interest Rate Premium) default earlier at expected lower CLTVs (i.e., higher house values relative to the loan amount) and might be expected to impose lower losses on lenders. The next section studies the realized losses.

\subsection{Analysis of realized losses}

In this section, we analyze the losses as a percent of loan balance at the time of default in a stylized manner. The total loss from a default is defined as the sum of the loss on the sale of the property plus interest expense plus other expenses (e.g., legal and maintenance). This identity allows us to decompose the total losses into the components and identify the specific drivers of the three components as well as the total loss. When regressing the additive expenses on an identical set of regressors, the sum of the resulting coefficients will add to the coefficient for total losses (subject to rounding error).

Each component of expense is regressed on a set of borrower and collateral characteristics and the "Slow Foreclosure State" indicator. Table 4 displays the results. Total losses are about half due to the loss on sale, and a quarter each to other expenses and interest expenses.

\subsection{Sale loss expense}

The first model in Table 4 explains the "Sale Loss Expense" defined as one minus the net sale proceeds divided by loan balance. The loss on the sale of the collateral can be influenced by a complex set of factors. In addition to the borrower's stopping strategy, three other considerations play a role. First is the condition of the property. The condition may be related to the age of the property, the quality of construction, and to borrower maintenance and time to foreclosure. Second is the atypicality of a property. Unusual properties may be more difficult to sell and impose larger losses on the lender. Finally, some borrowers may systematically overpay for properties due to lack of knowledge. The results in Table 4 for "Sale Loss Expense" include the net effects of all these factors, which cannot be easily isolated.

The coefficients on the property characteristic variables tell us that the losses from sale are higher for manufactured housing and for older homes. The economic significance of these variables is very high with losses 17 percent higher for manufactured housing and almost 4 percent per decade higher for older homes. Manufactured housing is generally considered to be of lower quality with higher depreciation rates than site-built housing. Older homes tend to be more atypical and require more maintenance. Atypical homes are also less liquid and sell with wider bid-ask spreads (see Capozza et al., (2005)).

Among the borrower characteristics, weaker borrowers (higher interest rate premium) and non-occupants cause significantly higher losses for lenders. "Low Documentation" borrowers impose smaller sale losses. 


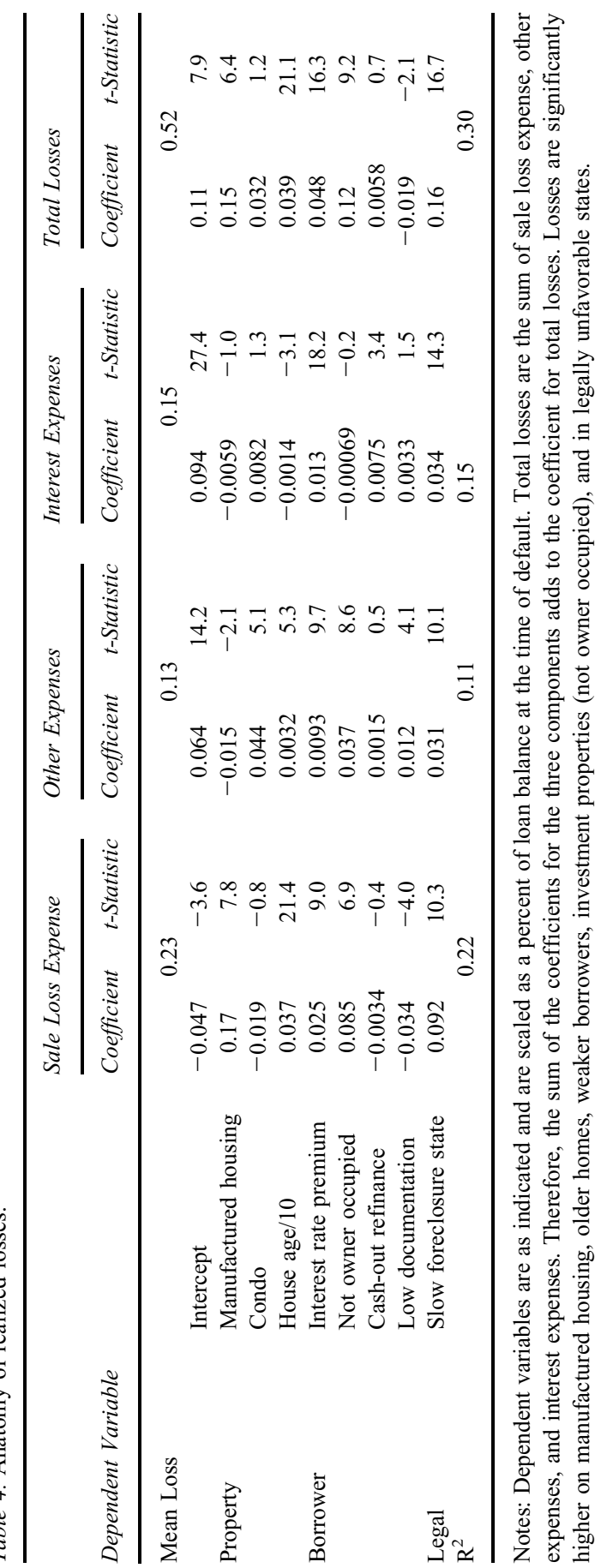


Slow foreclosure process adds over 9 percent to the sale loss. Whether this is due to depreciation of prices or to deterioration of the property during foreclosure cannot be determined.

\subsection{Other expenses}

For "Other Expenses" (second model in Table 4), condos and older homes impose larger losses. Weak borrowers and non-occupants also increase Other Expenses. Slow Foreclosure adds an additional 3 percent to Other Expenses. During the foreclosure process, unlike for fee-simple housing, condo fees accumulate and must be paid at or before sale. Weak (poor credit) borrowers and non-occupants are likely to impose more depreciation on properties.

\subsection{Interest expenses}

Higher interest expenses should arise if the property is in foreclosure for a longer period of time and if the coupon on the loan is higher. In the "Interest Expenses" column, the Interest Rate Premium and the Slow Foreclosure State indicator are highly significant.

\subsection{Total losses}

The major determinants of Total Losses include manufactured homes (15 percent higher), older homes (about 4 percent higher per decade), weak borrowers (almost 5 percent higher per percent of interest rate premium), non-occupants (12 percent higher), and slow foreclosure (16 percent higher).

Not surprisingly, the effect of the property indicators on total losses arises primarily from the additional losses on sale. Weak borrowers affect total losses through all three expense components. Non-occupants affect total losses through sale losses and other expenses. Slow foreclosure affects all three component expenses.

To summarize this section, less than half of total losses arise from the sale of the property. The other half includes interest expenses and other (legal and maintenance) expenses. All three categories of variables, borrower and collateral characteristics and the foreclosure process are important determinants of total losses. Losses on mortgages to subprime borrowers are higher than for better borrowers despite the shorter time to default of subprime borrowers.

\section{Conclusions}

The process in which borrowers default on mortgages and lenders eventually realize losses is a complex one involving several stages, many parties, and considerable time. Traditional approaches in the academic literature have focused on loss severity from the 
perspective of option pricing. However, option-pricing variables are difficult to quantify in many cases and, although significant, have surprisingly little power to explain the variation in these decisions.

In this research, we have explored loss severity for subprime mortgages using a rich dataset that includes much detail on the borrower and the collateral as well as on the various expenses that compose total losses. We find that borrower characteristics play an important role in determining both the stopping boundary and eventual total losses. Property characteristics and legal requirements are mainly important in explaining the various expenses that compose total losses. Similar to other research studies, we find that trigger events do not have the predicted impact on these decisions.

The market-adjusted current LTVs at the time of default are actually lower than at origination, on average. This implies that idiosyncratic factors play an important role in defaults on mortgage loans. That is, the loans in our sample did not default because there were significant declines in collateral prices in local housing markets. Rather, they defaulted despite increases in market prices.

One idiosyncratic factor is the creditworthiness of the borrower. Weaker subprime borrowers default earlier, which should result in lower losses on sale of the collateral. Nevertheless, lenders lose more on defaulted loans to weak borrowers relative to the balance at the time of default. We conjecture that there are three possible reasons for this result. First, subprime borrowers may be less skilled at property care and maintenance. If so, lenders will recover the defaulted properties in worse condition and be forced to sell at a lower price or pay substantial rehabilitation expenses. The significance of borrower creditworthiness in the Other Expenses regression supports this scenario. Second, subprime borrowers may be less knowledgeable about property values and may overpay for the properties relative to market prices. Third, subprime borrowers may be buying properties that appreciate less or deteriorate faster. This scenario could occur if borrowers buy properties with characteristics for which we cannot control such as properties in declining neighborhoods.

It has been widely documented that borrowers with poor credit histories have higher default rates. In this study, we have documented that weak borrowers also impose higher losses given a default. The higher losses arise from all three components of losses: lower sale prices; higher interest expenses; and higher legal and maintenance expenses.

\section{Acknowledgments}

Originally prepared for the Credit Research Center Subprime Lending Symposium in Washington, D.C., September 2002. We thank the discussant, James Barth, and the reviewers for helpful comments.

\section{Notes}

1. The use of option theory in mortgage analysis dates from as early as Findlay and Capozza (1977). More modern treatments commence with Foster and Van Order (1984). 
2. A heated debate in the mortgage literature has centered on whether borrowers do in actuality default optimally. Like the early debates about the efficient markets hypothesis, the concept of optimal default can easily degenerate into a tautology unless "optimal" is defined carefully. Because of the complexity of the decision, one would not expect simplified models to fully capture the complexity so that we should expect to see "non-optimal" behavior as defined by simplified models.

3. The model is similar in spirit to those in Kau and Keenan (1999) and Lekkas et al. (1993).

4. When interest rates fall, the likely outcome is for the borrower to refinance which leads to the asymmetric result.

5. Fair Isaac Co. reports that a credit score of 575 puts a borrower in the bottom 10 percent.

\section{References}

Ambrose, B. W., R. J. Buttimer, Jr., and C. A. Capone, Jr. (1997). "Pricing Mortgage Default and Foreclosure Delay," Journal of Money Credit Bank 29(3), 314-325.

Ambrose, B. W., C. A. Capone, and Y. Deng. (2001). "Optimal Put Exercise: An Empirical Examination of Conditions for Mortgage Foreclosure," Journal of Real Estate Finance Economics 23(2), 213-234.

Capozza, D. R., D. Kazarian, and T. A. Thomson. (1997). "Mortgage Default in Local Markets," Real Estate Economics 25(4), 631-655.

Capozza, D. R., D. Kazarian, and T. A. Thomson. (1998). "The Conditional Probability of Mortgage Default," Real Estate Economics 26(3), 359-389.

Capozza, D. R., R. D. Israelsen, and T. A. Thomson. (2005). “Appraisal, Agency and Atypicality: Evidence from Manufactured Homes," Real Estate Economics forthcoming.

Chan, K. C., A. Karolyi, F. Longstaff, and A. Saunders. (1992). "An Empirical Comparison of Alternative Models of the Short-Term Interest Rate," Journal of Finance 47, 1209-1227.

Crawford, G., and E. Rosemblatt. (1995). "Efficient Mortgage Default Option Exercise: Evidence from Loss Severity," Journal of Real Estate Research 19(5), 543-555.

Findlay, M. C., and D. R. Capozza. (1977). "The Variable Rate Mortgage and Risk in the Mortgage Market," Journal of Money, Credit, and Banking 9, 356-364.

Foster, C., and R. Van Order. (1984). "An Option-Based Model of Mortgage Default," Housing Finance Review 3, $351-372$.

Hull, J. C. (1993). Options, Futures, and Other Derivative Securities, Second edition. Englewood Cliffs, New Jersey: Prentice Hall.

Jones, L. D. (1993). "Deficiency Judgments and the Exercise of the Default Option in Home Mortgage Loans," Journal of Law and Economics 36, 115-138.

Kau, J. B., and D. C. Keenan. (1999). "Patterns of Rational Default," Regional Science and Urban Economics 29(6), 765-785, Nov.

Kau, J. B., D. C. Keenan, and T. Kim. (1994). “Default Probabilities for Mortgages," Journal of Urban Economics.

Lekkas, V., J. M. Quigley, and R. Van Order. (1993). "Loan Loss Severity and Optimal Mortgage Default," Journal of the American Real Estate and Urban Economics Association 21(4), 353-371. 